\title{
PORTA-ENXERTOS PARA O CULTIVAR MÁXIMO IAC 138-22 DE UVAS DE VINHO EM MONTE ALEGRE DO SUL, SP( $\left.{ }^{1}\right)$
}

\author{
MAURILO MONTEIRO TERRA (2,0), ERASMO JOSE PAOLI PIRES (2), \\ SONIA MARIA BONILHA MARCONDES COELHO (4) \\ ILENE RIBEIRO DA SILVA PASSOS (2), RUI RIBEIRO DOS SANTOS ( 3 ), \\ CELSO VALDEVINO POMMER (2,0), ANDRE CAMARGO PEREIRA DA SILVA $(2)$ \\ - IVAN JOSÉ ANTUNES RIBEIRO (5)
}

RESUMO

Em Monte Alegre do Sul, SP, efetuou-se um experimento de longa duraço para observar o comportamento do cultivar IAC 138-22 (Máximo) de uvas para vinho, sobre cinco porta-enxertos: RR 101-14, 'Golia', 'Ripária do Traviút, IAC 572 e IAC 313. Em oito colheitas sucessivas anuais, de 1974 a 1981 , analisaram-se as produçoses médias de uvas por planta. Os resultados indicaram que o IAC 572' foi o melhor porta-enxerto para o IAC 138-22 'Máximo'. O IAC 313 superou o IAC 572 em um dos anos estudados. Todos os outros porta-enxertos apresentaram desempenho inferior.

Termos de indexaçso: videire, uve, porta-enxerto, cultuvar IAC 138-22.

\section{ABSTRACT}

\section{ROOTSTOCKS FOR WINE GRAPE CULTIVAR IAC 138-22}

A long term experiment was conducted at Monte Alegre do Sul, State of Săo Paulo, Brazil, to study the behaviour of wine grape cultivar IAC 138-22 Máximo on five rootstocks: RR 101-14, 'Golia', Ripária do Traviú', IAC 313 and IAC 572. The yields of eight consecutive annual harvests (from 1974 to 1981) were analysed. The results indicated that IAC 572 was the best rootstock. IAC 313 can also be used but with fair results. 'Riparia do Traviú',

\footnotetext{
(1) Recebido para publicação om 19 de maio de 1989 e aceito em 17 de agosto de 1990.

(i) Seçāo de Viticuluura, instituto Agronómico (IAC), Caixa Postal 28, 13001 Cempinas, SP.

(3) Estaça Exporimentsll de Monte Alogre do SUl, IAC.

(4) Serviço de Introdução o Quarentene de PlantBe, IAC.

(5) Soçäo de Microbiologia Fitotocnice, IAC.

(5) Com bolse do pesquise do CNPq.
} 
RR 101-14 and 'Golia' are not recommended as rootstocks for IAC 138-22. Considering the row spacing $(2 \times 1 \mathrm{~m})$ which allows 5,000 plants $/$ a, the difference between average yields of the best and the worst rootstock was $8,475 \mathrm{~kg} / \mathrm{ha}$ of grapes, a considerable figure for the grape grower.

Index terme: wine, grepe, rootstock, wine Cv. IAC 138-22.

\section{INTRODUÇÃO}

Mais de $75 \%$ do vinho produzido no Brasil e obtido a partir de uvas de cultivares americanos ou hibridos. No Rio Grande do Sul, o principal cultivar 6 Isabel, o que o faz o mais plantado no Pals (COPAT, 1987). Em São Paulo, são cultivados, além do 'Isabel', o híbrido 'Seibel 2', o Niagara Branca' e o Niagara Rosada'. Nos últimos anos, vem aumentando a área cultivada com o hibrido IAC 138-22, originado do programa de melhoramento genético da videira no Instituto Agronomico (OJIMA et al., 1984).

Embora no seu lançamento oficial os autores tenham oferecido algumas opçöes de porta-enxertos para esse cultivar (SANTOS NETO et al., 1968) como primeira aproximação, a indicação mais confiável só poderia ser feita com base em uma sérié histórica de dados.

Para obtenção de dados conclusivos sobre o comportamento do 'IAC 138-22' sobre diferentes porta-enxertos, foi elaborado este estudo, iniciado em 1966, antes até do lançamento do cultivar, e encerrado em 1982.

\section{MATERIAL E MÉTODOS}

O cultivar-copa utilizado foi o hibrido IAC 138-22, resultante do cruzamento entre Seibel 11.342 a Syrah. O primeiro é um hibrido introduzido da França e, o segundo, também frances, um cultivar de Vitis vinifera. Suas características agronomicas e enologicas se encontram detalhadas em SANTOS NETO et al. (1968).

Os porta-enxertos utilizados foram os seguintes:

'Ripária do Traviú' - Introduzido da França, trata-so, de fato, do 106$8 \mathrm{Mgt}$ e tem sido o mais utilizado em Sảo Paulo. Apresenta desenvolvimento satisfatorio praticamente em todos os tipos de solo e possui afinidade com a maioria dos cultivares plantados comercialmente no Estado, sendo muito usado como porta-enxerto do 'Niagara' (PEREIRA \& LEITÃO F.․, 1973).

RR 101-14 - Também introduzido da França, apresenta características semelhantes às do 'Ripária do Traviú', tanto na adaptação aos diferentes tipos de solo quanto na afinidade com grande número de cultivares. De modo geral, é inferior ao 'Ripária do Traviú' com 'Niagara' (PEREIRA \& LEITÃO F.', 1973). 
'Golia' - Introduzido da Itália, 6 especialmente adaptado para terrenos profundos, leves ou pesados, e revela afinidade com a maioria dos cultivares em uso. Suas estacas apresentam bom pegamento, mas as folhas sofrem ataques da antracnose do midio. As uvas do Niagara' produzem muito bem quando enxertadas sobre 'Golia', porém os cachos são muito compactos e, as bagas, pequenas (PEREIRA \& LEITAOO F.', 1973).

IAC 313 - 'Tropical', foi obtido por Santos Neto no Instituto Agronomico de Campinas e entregue ao cultivo em 1955. Por suas características, é especialmente indicado para regiōes com temperaturas médias anuais elevadas, como o noroeste do Estado de São Paulo e o submédio São Francisco, onde seus ramos não hibernam adequadamente (POMMER, 1989). Sua descriçāo botanica completa se encontra em PEREIRA \& LEITAO F. ${ }^{\circ}$ (1973).

IAC 572 - Obtido por Santos Neto no IAC, resultante do cruzamento Vitis caribaea XRR 101-14, apresenta ótimo vigor, tento nos solos argilosos como nos arenosos e folhas resistentes às doenças criptogâmicas. Vem sendo experimentado com diversos cultivares comerciais, com resultados promissores (PEREIRA \& LEITÃO F. ${ }^{\circ}$, 1973).

O experimento foi instalado em 1966 na Estação Experimental de Monte Alegre do Sul, SP, situada a $740 \mathrm{~m}$ de altitude, latitude de $22^{\circ} 43$ 'S e longitude de $46^{\circ} 37 \mathrm{~W}$, em solo podzolico vermelho-amarelo.

0 delineamento experimental foi de blocos ao acaso, com cinco tratamentos $\theta$ seis repetições, sendo as parcelas constituidas por cinco plantas, no espaçamento de $2 \times 1 \mathrm{~m}$.

Anotaram-se os dados referentes a produção por oito colheitas anuais consecutivas, de 1974 a 1981, e ao número de cachos por planta, por tês colheitas (1980, 1981 e 1982).

\section{RESULTADOS E DISCUSSÃO}

Os resultados obidos quanto à produçāo de uvas estäo no quadro 1.

Em tres dos quatro anos em que $o$ teste $F$ mostrou haver diferenças entre tratamentos, o IAC 572 superou os demais porta-enxertos. Mesmo nos anos em que as diferenças não foram estatisticamente significativas, as produçōes absolutas obtidas nas plantas enxertadas sobre o IAC 572 foram maiores que as dos outros.

O IAC 313 foi estatisticamente superior a todos os outros porta-enxertos em 1975. Em 1974, foi superior ao 'Ripária do Traviú'e ao RR 101-14, não diferindo do 'Golia'.

Na média dos oito anos, o IAC 572 comprovou sua superioridade, permitindo que as produçōes do 'Máximo' fossem majores quando enxertado sobre ele. Os demais porta-enxertos tiveram comportamento semelhante no conjunto dos dados. 


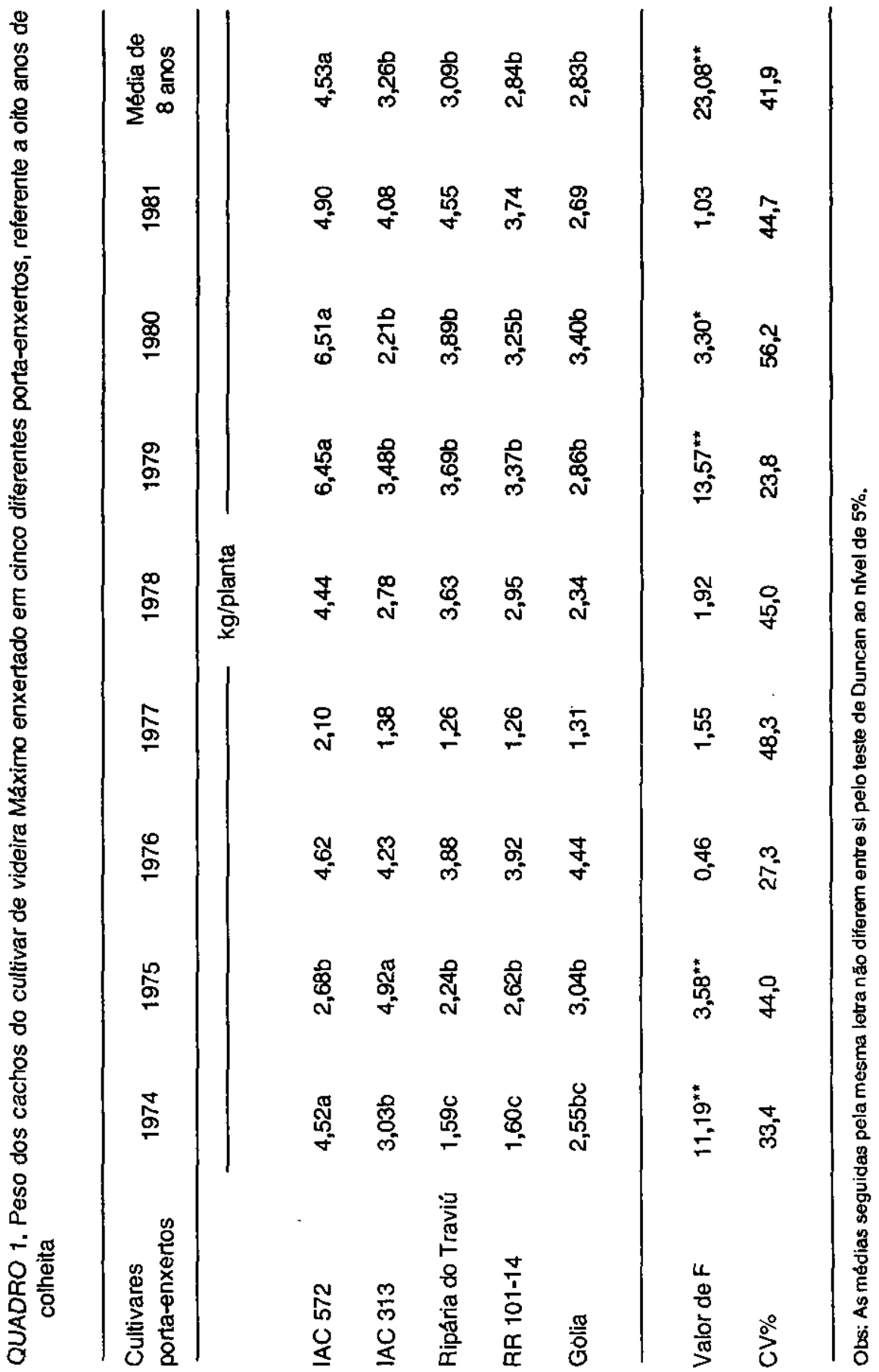




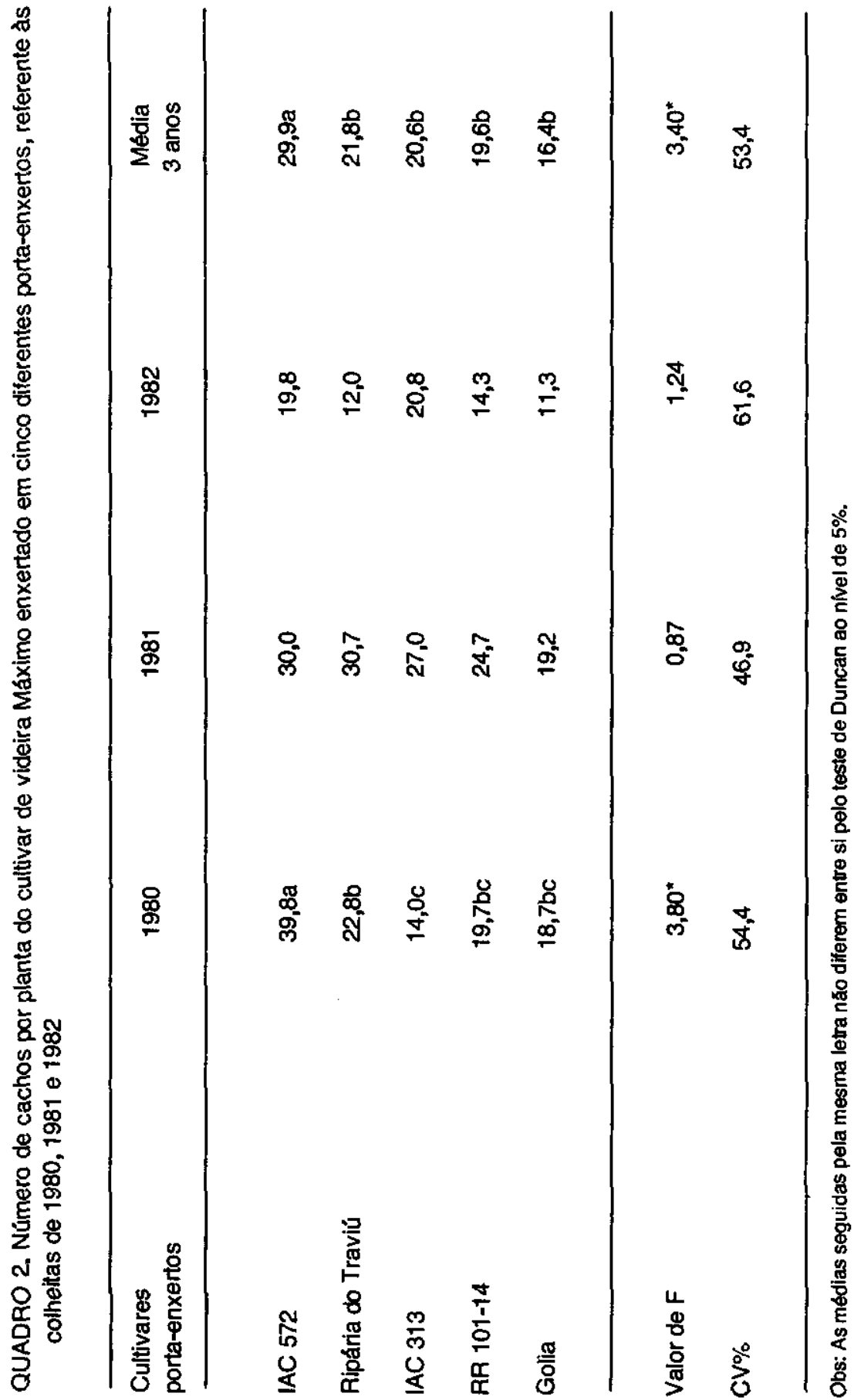


A significancia da interação tratamentos $x$ anos certamente deveu-se à alternancia de melhor produtividade mostrada por IAC 572 e IAC 313. Entretanto, esse fato apenas não é suficiente para tirar os méritos do IAC 572, destacadamente o melhor porta-enxerto para o 'Máximo'.

Quanto a cachos por planta, outo indicador de produtividade, verifica-se - Quadro 2 - que, em 1980, o IAC 572 induziu o maior número deles no 'Máximo'. Considerando-se a média dos tes anos, o IAC 572 também foi superior aos demais porta-enxertos.

De modo geral, o IAC 572 destacou como o melhor porta-enxerto para o cultivar de uvas para vinho IAC 138-22 Máximo. O IAC 313 apareceu como alternativa graças a seu desempenho em um dos anos. O 'Ripária do Traviú', o RR 101-14 e o Golia não são recomendados para porta-enxerto do 'Máximo'.

No trabalho que lançou o cultivar IAC 138-22 (SANTOS NETO et al., 1968), os autores indicavam sua enxertia sobre alguns porta-enxertos como 'Rupestris du Lot', 'Golia', 'Ripária do Traviú' e IAC 313, informando sobre melhores resultados com o 'Ripária do Traviú' e 'Golia'. Entretanto, neste trabalho, de longa duração, os resultados não dão suporte a tais indicações, especialmente as referentes ao 'Golia' e ao 'Ripária do Traviú'.

Deve-se ressaltar que, do ponto de vista prático, isto é, do viticultor, o significado desses resultados é muito relevante economicamente. A diferença entre a média de produção obtida com o melhor porta-enxerto, IAC 572, e aquela com os dois piores ('Golia' e RR 101-14) é de 1,7kg/planta. Ora, num espaçamento como o que foi utilizado $(2 \times 1 \mathrm{~m})$, tem-se 5.000 plantas por hectare. A diferença atingiria o total de $8.475 \mathrm{~kg} / \mathrm{ha}$, ou 5.085 litros/ha de vinho. Dessa forma, sem nenhuma despesa adicional, o produtor melhorará sensivelmente seus ganhos por unidade de área, apenas com a utilização do porta-enxerto recomendado.

\section{CONCLUSÕES}

1. O cultivar IAC 572 mostrou-se como o melhor porta-enxerto para o híbrido IAC 138-22, produtor de uvas para vinho.

2. O IAC 313 apresentou-se como uma opção razoável como porta-enxerto do IAC 138-22 'Máximo'.

3. O 'Máximo' não deve ser enxertado sobre 'Riparia do Traviú', 'Golia' e RR 101-14, sob pena de perdas consideráveis ao longo dos anos.

\section{REFERENCIAS BIBLIOGRÁFICAS}

COPAT, L. Proposta para melhora de qualidade do vinho de uvas híbridas e americanas. In: SIMPOSIO LATINO-AMERICANO DE ENOLOGIAE VITICULTURA, 2.; JORNADA LATINO-AMERICANADE VITICULTURAE ENOLOGIA, 2., e SIMPOSIO ANUAL DE VITIVINICULTURA, 2., Garibaldi/Bento Gonçalves, 1987. Anais. Bento Gonçalves, Associaçăo Brasileira dos Técnicos em Viticultura e Enologia, 1987. p.87-91. 
OJIMA, M.; RIGITANO, O.; CAMPO-DALLORTO,F.A.; BARBOSA, W.; RIBEIRO, I.J.A.; TERRA, M.M.; AMARO, A.A.; BILLER, V.S.P.; BETTI, J.A.; KUNIYUKI, H.; MARTINS, F.P.; SCARANARI, H.J. \& FAHL, J.I. Fruticultura de clima temperado no Estado de Säo Paulo: diagnóstico da situação economica e cultural e atividades de pesquisa no IAC. Campinas, Instituto Agronomico, 1984. 72p. (Boletim tócnico, 89)

PEREIRA, F.M. \& LEITÃO FILHO, H. de F. Caracterização botanica de porta-enxertos de videira. Campinas, Instituto Agronomico, 1973. 20p. (Boletim técnico, 7$)$

POMMER, C.V. O melhoramento genético da videira no LAC. Campinas, Instituto Agronomico, 1989. 40p. (Datilografado)

SANTOS NETO, J.R. de A.; PEREIRA, F.M.; MARTINS, F.P. \& LEITĀO FILHO, H. de F. Características e possibilidades do cultivar de videira IAC 138-22. O Aoronómico, Campinas, 20(9-10):1-8, 1968. 